\title{
Emergency Atypical Resection for Perforated Gastric Gist
}

\author{
Manuel Muinelo Lorenzo, Lucia Dorado Castro, Maria Isabel Perez Moreiras, \\ Jose Conde Vales, Jose Antonio Costa Buján \\ Department of General Surgery and Digestive Diseases, Lucus Augusti Universitary Hospital, Lugo, Spain \\ Email: manuelmuinelo@hotmail.com, lucdoca@hotmail.com, isapm44@hotmail.com, \\ Jose.Conde.Vales@sergas.es, Jose.Antonio.costa.bujan@sergas.es
}

Received 17 January 2014; revised 22 February 2014; accepted 2 March 2014

Copyright () 2014 by authors and Scientific Research Publishing Inc. This work is licensed under the Creative Commons Attribution International License (CC BY). http://creativecommons.org/licenses/by/4.0/

(c) $\underset{\mathrm{EY}}{\mathrm{C}}$ Open Access

\begin{abstract}
We report the case of a 77-year-old male who came to the emergency department with epigastric pain accompanied by fever and chills. After the diagnosis of intra-abdominal abscess and gastric tumor, emergency surgery was performed with resection of the tumor and abscess drainage. The patient had a good postoperative course.
\end{abstract}

\section{Keywords}

\section{GIST; Gastrectomy; Intra-Abdominal Abscess}

\section{Introduction}

Gastrointestinal stromal tumors (GIST) are specific mesenchymal tumors of the digestive tract. They were described first by Mazor and Clark (1983) [1]. They originate from the interstitial cells of Cajal [2]. Its most common site is the stomach (50\% - 60\%) [3] and small intestine (25\% - 30\%), and extremely rare in the esophagus, colon, rectum and appendix [4]. There are additional locations at digestive gallbladder, pancreas, liver and bladder. It is usually an incidental finding on imaging for the study of other diseases.

\section{Case Report}

A 77-year-old male came to the emergency with epigastric pain radiating to the left upper quadrant of abdomen accompanied with fever and chills without nausea or vomiting.

His medical history includes Sd Bechet, Herpes Zoster, pneumonia, prostate adenoma and vena cava thrombosis.

Abdominal examination revealed the presence of abdominal pain and distension without evidence of peritonitis. In blood test was observed the presence of leukocytosis.

Abdominal ultrasound and CT showed retrogastric collection of $15 \mathrm{~cm}$ (Figure 1). Emergency atypical gastric 


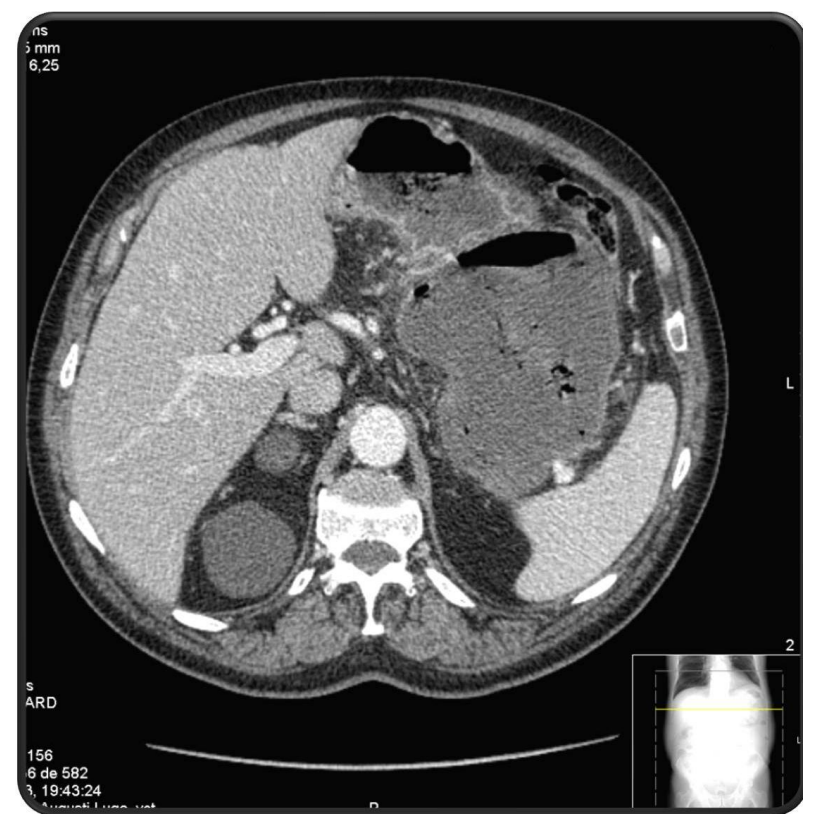

Figure 1. Perforated GIST with retrogastric collection.

resection was performed because of a perforated gastric tumor with peritoneal implants and splenic hilum extension. Histopathology revealed a gastric GIST. In subsequent tests no disease recurrence was observed. The treatment was completed with adjuvant therapy with Imatimib.

\section{Discussion}

Gastrointestinal stromal tumors are extremely rare. The perforation is an exceptional presentation.

The clinical features are variable and depend on the size and location of the tumor. The most common signs and symptoms are mass effect and bleeding accompanied by abdominal discomfort and rarely with complications [5] [6]. Perforation is extremely rare. There are 16 cases in medical literature of GIST tumors with this debut, all in jejunum [7], including a jejunal diverticulum [8]. No documented cases of gastric perforation until today, but there is an esophageal perforation [9].

Surgery is the only potentially curative treatment. It should be made a R0 resection with clear margins of 1 - 2 cm preventing rupture of the tumor [10] [11]. Lymphadenectomy is not required.

Treatment with inhibitors of tyrosine kinase receptor (imatinib) marked a big change in the prognosis of GIST tumors has led to increased survival rates. The age of presentation, anatomic location, size and histology are the most important prognostic factors [5] [11].

\section{Conclusion}

The diagnosis of perforated gastric GIST tumor should be considered in emergency surgery as a differential diagnosis even when it is a rare entity in clinical practice.

\section{References}

[1] Efremidou, E.I., Liratzopoulos, N., Papageorgiou, M.S. and Romanidis, K. (2006) Perforated GIST of the Small Intestine as a Rare Cause of Acute Abdomen: Surgical Treatment and Adjuvant Therapy. Case Report. Journal of Gastrointestinal and Liver Diseases, 15, 297-299.

[2] Kindblom, L.G., Remotti, H.E., Aldenborg, F. and Meis-Kindblom, J.M. (1998) Gastrointestinal Pacemaker Cell Tumor (GIPACT): Gastrointestinal Stromal Tumors Show Phenotypic Characteristics of the Interstitial Cells of Cajal. The American Journal of Pathology, 152, 1259-1269.

[3] Oida, Y., Motojuku, M., Morikawa, G., Mukai, M., Shimizu, K., Imaizumi, T., et al. (2008) Laparoscopic-Assisted Resection of Gastrointestinal Stromal Tumor in Small Intestine. Hepato-Gastroenterology, 55, 146-149. 
[4] Connolly, E.M., Gaffney, E. and Reynolds, J.V. (2003) Gastrointestinal Stromal Tumours. The British Journal of Surgery, 90, 1178-1186. http://dx.doi.org/10.1002/bjs.4352

[5] Shah, S.N. (2007) Malignant Gastrointestinal Stromal Tumor of Intestine: A Case Report. Indian Journal of Pathology \& Microbiology, 50, 357-359.

[6] Gupta, A., Gupta, S., Tandon, A., Kotru, M. and Kumar, S. (2011) Gastrointestinal Stromal Tumor Causing Ileo-Ileal Intussusception in an Adult Patient a Rare Presentation with Review of Literature. The Pan African Medical Journal, 8, 29. http://dx.doi.org/10.4314/pamj.v8i1.71086

[7] Steigen, S.E., Bjerkehagen, B., Haugland, H.K., Nordrum, I.S., Loberg, E.M., Isaksen, V., et al. (2008) Diagnostic and Prognostic Markers for Gastrointestinal Stromal Tumors in Norway. Modern Pathology, 21, 46-53. http://dx.doi.org/10.1038/modpathol.3800976

[8] Wilson, S.L. and Wheeler, W.E. (1992) Giant Leiomyoma of the Small Intestine with Free Perforation into the Peritoneal Cavity. Southern Medical Journal, 85, 667-668. http://dx.doi.org/10.1097/00007611-199206000-00024

[9] Memmi, N., Cipe, G., Bektasoglu, H., Toydemir, T., Kadioglu, H., Bozkurt, S., et al. (2012) Perforated Gastrointestinal Stromal Tumor in the Jejunum: A Rare Cause of Acute Abdomen. Oncology Letters, 4, 1244-1246.

[10] Shoji, M., Yoshimitsu, Y., Maeda, T., Sakuma, H., Nakai, M. and Ueda, H. (2013) Perforated Gastrointestinal Stromal Tumor (GIST) in a True Jejunal Diverticulum in Adulthood: Report of a Case. Surgery Today, 1-7.

[11] Sjogren, P.P., Banerji, N., Batts, K.P., Graczyk, M.J. and Dunn, D.H. (2013) Rare Presentation of a Gastrointestinal Stromal Tumor with Spontaneous Esophageal Perforation: A Case Report. International Journal of Surgery Case Reports, 4, 636-639. http://dx.doi.org/10.1016/j.ijscr.2013.02.029 